\title{
O IMPACTO DA COVID-19 MEDIADO PELA RESILIÊNCIA HUMANA EM MICROEMPREENDORES DO RAMO DA BELEZA
}

\section{THE IMPACT OF COVID-19 MEDIATED BY HUMAN RESILIENCE IN MICROENTREPRENEURS IN THE BRANCH OF BEAUTY}

\section{ALINE FRANCILURDES NERY DO VALE}

Mestranda em Administração - Universidade Federal Rural do Semi-Árido (UFERSA)

Orcid: https://orcid.org/0000-0001-5876-4730 / E-mail: alinefrancilurdes@hotmail.com Av. Francisco Mota, 572, Departamento de Ciências Sociais a Aplicadas - Bairro Costa e Silva, Mossoró, RN - CEP: 59625-900

\section{JULIANA CARVALHO DE SOUSA}

Doutoranda em Administração

Docente da Universidade do Estado do Rio Grande do Norte (UERN)

Orcid: https://orcid.org/0000-0002-0388-3959 / E-mail: juli.cs1009@gmail.com

\section{AGOSTINHA MAFALDA BARRA DE OLIVEIRA}

Doutora em Psicologia Social e Antropologia das Organizações Universidade Federal Rural do Semi-Árido (UFERSA)

Orcid: https://orcid.org/0000-0002-6055-1758 / E-mail: agostinhamafalda@ufersa.edu.br

\section{SUZANA VIRGÍNIA DA COSTA REGIS}

Mestranda em Administração - Universidade Federal Rural do Semi-Árido (UFERSA) Orcid: https://orcid.org/0000-0002-0282-8296 / E-mail: suzanavdcr@hotmail.com

\section{JOYCE SILVA SOARES DE LIMA}

Graduada em Administração - Universidade Federal Rural do Semi-Árido (UFERSA) Orcid: https://orcid.org/0000-0001-6852-5899 / E-mail: joycessdl@hotmail.com

Submissão: 16/05/2020. Revisão: 08/11/2020. Aceite: 26/11/2020. Publicação: 29/12/2020. DOI: http://dx.doi.org/10.22277/rgo.v14i1.5488

\section{RESUMO}

Esta pesquisa tem como objetivo analisar o grau de resiliência dos microempreendedores individuais que atuam no ramo da beleza em uma cidade do Rio Grande do Norte durante a pandemia da COVID-19. Para fins metodológicos, este estudo possui caráter descritivo de cunho quantitativo. Foram realizadas entrevistas virtuais, por meio do aplicativo WhatsApp, em cumprimento a recomendação de isolamento social (OMS, 2020), com dez microempreendedoras do ramo da beleza da cidade de Mossoró-RN. Para a compreensão dos relatos obtidos, foi utilizada a técnica da Análise de Núcleos de Sentido (ANS), adaptada por Mendes (2007). Quanto aos resultados dos dados, emergiram-se novas categorias associadas às dimensões da resiliência humana proposta por Perim et al. (2015). Com base nos relatos apresentados, de forma geral, as entrevistadas apresentaram baixos níveis de resiliência humana. Desse modo, o estudo possui relevância gerencial ao considerar e analisar esse constructo como um traço de personalidade necessário para enfrentar momentos de crise e de competitividade organizacional. Além disso, tem-se a relevância acadêmica da pesquisa, visto que não foram encontrados estudos sobre resiliência de microempreendedores no contexto da pandemia da COVID-19, tornando este um gap de pesquisa.

Palavras-chave: Resiliência. Microempreendedores. Setor da beleza. 
O impacto da COVID-19 mediado pela resiliência humana em microempreendores do ramo da beleza

\begin{abstract}
This research aims to analyze the degree of resilience of individual microentrepreneurs who work in the beauty industry in a city in Rio Grande do Norte during the COVID-19 pandemic. For methodological purposes, this study has a descriptive character of a quantitative nature. Virtual interviews were conducted through the WhatsApp app, in compliance with the recommendation of social isolation (WHO, 2020), with ten micro-entrepreneurs in the beauty industry in the city of Mossoró-RN. To understand the reports obtained, we used the technique of Analysis of Nuclei of Sense (ANS), adapted by Mendes (2007). As for the results of the data, new categories emerged associated with the dimensions of human resilience proposed by Perim et al. (2015). Based on the reports presented, in general, the interviewees showed low levels of human resilience. Thus, the study has managerial relevance when considering and analyzing this construct as a personality trait necessary to face moments of crisis and organizational competitiveness. In addition, there is the academic relevance of the research, since there were no studies on resilience of micro-entrepreneurs in the context of the COVID-19 pandemic, making this a research gap.
\end{abstract}

Keywords: Resilience. Microentrepreneurs. Beauty sector.

\title{
1 INTRODUÇÃO
}

A COVID-19 alcançou desmedidas proporções. Em meados de fevereiro de 2020 mais de 72.500 pessoas já haviam sido infectadas e mais de 1.800 pacientes morreram em Wuhan, cidade da China, onde a epidemia foi identificada pela primeira vez (XIAO et al., 2020).

No entanto, diversos países passaram a notificar casos da doença causada pelo novo coronavírus (SARS-CoV-2), levando governos de todo o mundo a tomarem medidas de contenção, na tentativa de amenizarem os impactos sobre a economia e a saúde (CRAVEN et al., 2020). Posteriormente, a Organização Mundial da Saúde (OMS, 2020) declarou a doença como uma Emergência de Saúde Pública de Interesse Internacional.

O surto da COVID-19 passou a afetar o ambiente de negócios na China (AL-AWADHI et al., 2020). O mercado de ações globais também foi atingido com uma perda de US \$ 6 trilhões no final de fevereiro. No Brasil, o Boletim de Impactos e Tendências da COVID-19 nos pequenos negócios, apresentado pelo Serviço Brasileiro de Apoio às Micro e Pequenas Empresas (SEBRAE) mostrou consideráveis perdas em pelo menos 14 segmentos, incluindo turismo, eventos, moda, artesanato e beleza, com queda no faturamento de $88 \%, 86 \%, 80 \%$, $70 \%$ e $69 \%$ respectivamente. Nesse contexto, os serviços de beleza ocupam a quinta posição, sendo um dos mais afetados pela crise. Esse declínio tende a ser maior, por não serem produtos e serviços considerados essenciais em momento de pandemia (SEBRAE, 2020).

Diante do exposto, a resiliência humana surge como resposta às situações adversas que testam os limites das capacidades de enfrentamento dos indivíduos (KONRADT et al., 2018), sendo comumente conceituada como a capacidade de um indivíduo se adaptar rapidamente às mudanças e superar situações traumáticas ou estressantes, mantendo o bemestar e o equilíbrio emocional (SHIN et al., 2019). Nessa perspectiva, pessoas resilientes lidam de forma mais construtiva com mudanças no seu contexto de trabalho, inclusive com interrupções e perdas, pois usam contratempos como motivação e oportunidade de crescimento pessoal (ROBERTSON et al., 2015).

No entanto, não existe um conceito universal sobre a resiliência. Para alguns autores a resiliência é compreendida como um traço de personalidade, ou seja, uma característica do 
Aline Francilurdes Nery do Vale, Juliana Carvalho de Sousa, Agostinha Mafalda Barra de Oliveira, Suzana Virgínia da Costa Regis e Joyce Silva Soares de Lima

ser humano que não pode ser aprendida (LIU et al., 2018; OSHIO et al., 2018). Para outros, a resiliência é decorrente de um processo dinâmico de interação do indivíduo com o seu meio, que possibilita a adaptação apesar dos fatores estressores. Portanto, trata-se de uma capacidade que não pode ser desenvolvida sem a exposição a riscos ou adversidades (HORNOR, 2016; BEUTEL et al., 2017; MORETE et al., 2018; CRUZ et al., 2018).

Embora o interesse científico pela resiliência tenha crescido significativamente nos últimos anos (RICE; LIU, 2016; MARCHEZINI; FORINI, 2019), há incipientes pesquisas sobre a resiliência de microempreendedores. Ademais, não foram encontrados estudos sobre resiliência de microempreendedores; especificamente neste período de crise decorrente das medidas de isolamento social; até o momento, na Web of Science. Com vistas a preencher esta lacuna, este artigo tem como objetivo analisar o grau de resiliência dos microempreendedores individuais que atuam no ramo da beleza em uma cidade do Rio Grande do Norte durante a pandemia da COVID-19.

Os resultados deste estudo poderão orientar as organizações sobre como sobreviver à crise causada pela pandemia da COVID-19, uma vez que examina se a personalidade de um indivíduo associada aos seus traços de resiliência auxilia na mitigação ou superação da pandemia; inferindo, assim, a importância desta pesquisa no âmbito gerencial. Ademais, este estudo também apresenta relevância para a sociedade, uma vez que a sobrevivência das empresas em meio à crise contribui para que a economia não entre em colapso, evitando um aumento nas taxas de desemprego. Portanto, é importante investigar se pessoas mais resilientes sentem menos os impactos causados pela pandemia e, consequentemente, lidam com mais sabedoria na formulação de respostas eficazes à crise, conseguindo permanecer e/ou até se sobressair no mercado.

\section{REFERENCIAL TEÓRICO}

\subsection{MICROEEMPREENDEDORES E O SEGMENTO DE SERVIÇOS DE BELEZA}

Conforme o SEBRAE (2020), Microempreendedor Individual (MEI) é um empreendedor que tem um pequeno negócio e o conduz sozinho. A atividade determina que o profissional tenha um rendimento fixo anual de até $\mathrm{R} \$ \mathbf{8 1 . 0 0 0 , 0 0}$ ou mensal de $\mathrm{R} \$ 6.750,00$, além de não ter participação em outra empresa como sócio ou titular e ter no máximo um funcionário contratado que receba o salário mínimo ou o piso da categoria para se manter dentro dessa modalidade. O MEl surgiu por meio da Lei Complementar no 128, de 19 de dezembro de 2008, com o intuito de formalizar trabalhadores brasileiros que desempenhavam suas atividades sem amparo legal e jurídico.

Segundo dados da Agência SEBRAE de Notícias (2020), entre 2018 e 2019 o estado do Rio Grande do Norte passou de 101.273 para 120.758 pequenos negócios formalizados, sendo que mais de $60 \%$ correspondem ao segmento da beleza. Dentre os municípios com maior índice de cadastros no MEl estão: Natal, com 66.031, seguido por Parnamirim com 16.740 e, logo depois, Mossoró com 14.135.

Em adição, dados do Instituto Brasileiro de Geografia e Estatística (IBGE, 2019) sinalizam para a existência de que cerca de 23,8 milhões de trabalhadores informais no Brasil, dos quais 8.154,678 são MEl, conforme dados do Governo Federal, publicados no Portal do Empreendedor no ano de 2020. De acordo com o SEBRAE (2020), os serviços de estética e cuidados com a beleza correspondem a $170.360 \mathrm{MEls}$ cadastrados. No Rio Grande do Norte, esse setor é a segunda atividade mais desempenhada pelos microempreendedores, totalizando 7.747 de pequenos negócios em 2019. Nesse cenário, o mercado da beleza 
O impacto da COVID-19 mediado pela resiliência humana em microempreendores do ramo da beleza

alimenta uma ascensão que movimenta mais de $\mathrm{R} \$ 38$ bilhões por ano no Brasil e a formalização de MEls foi uma das categorias que mais cresceu acompanhando essa tendência. Além disso, a Agência SEBRAE de Notícias (2020) informou que o segmento da beleza é o que mais registra formalização de MEls no estado do Rio Grande do Norte.

Esse segmento é um dos que mais estão sendo impactados pelos efeitos de retração econômica ocasionada pela pandemia do coronavírus, especialmente por ser um setor que exige maior interação física com os consumidores. Essa queda levou as empresas a aderirem medidas emergenciais para reduzir custos e aumentar a receita, com o intuito de equilibrar o caixa durante essa crise.

\subsection{RESILIÊNCIA HUMANA}

O conceito de resiliência vem atraindo a atenção do mercado e da academia ao longo dos anos e evoluído devido aos sucessivos alargamentos científicos, dando origem a um conceito amplo da palavra (RODRIGUES et al., 2017). Resiliência pode ser definida como a capacidade de seguir em frente de forma positiva, a partir de experiências adversas, negativas ou traumáticas (IRIGARAY; PAIVA; GOLDSCHMIDT, 2017).

$\mathrm{O}$ termo resiliência se origina da palavra latina resilio, que significa o retorno a um estado prévio. $O$ vocábulo é utilizado em diferentes áreas do conhecimento, porém, ao se transpor o termo para as ciências humanas, seu significado foi definido como a aptidão de uma pessoa, mesmo em ambientes adversos, construir ou se reconstruir positivamente diante as dificuldades (KAMLOT, 2017). De forma semelhante, Beuren e Santos (2019) afirmam que ainda que o termo resiliência possa ser alterado nos diferentes campos do conhecimento, sua definição se relaciona com a capacidade de um elemento retornar a um estado estável após uma ruptura.

Segundo Molina, Santo e Pavón (2019), a resiliência é um processo dinâmico, não é algo que uma pessoa constrói sozinho no escuro, mas sim um processo facilitado pelo encontro com um ambiente que proporciona o reconhecimento da capacidade em si mesmo. Ser resiliente significa interpretar situações desconhecidas para criar formas de enfrentar esses eventos, além de recombinar pessoas, recursos e processos a fim de transformar essas escolhas (BEUREN; SANTOS, 2019).

Acrescido a isso, Pessotti et al. (2018) definem resiliência humana como a capacidade de uma adaptação bem-sucedida diante do estresse da adversidade. Resiliência não é invulnerabilidade ao estresse, e sim ser capaz de se recuperar de eventos negativos. Essa pode ser melhorada ao se investir uma rotina de compartilhamento de conhecimentos sobre mudanças relevantes no ambiente (SINCORÁ et al., 2018). Uma parcela da literatura acredita que a resiliência humana não é uma característica inata, ou seja, que nasce com o indivíduo, mas sim que essa característica se forma no curso da vida, a partir da interação do ser humano com o ambiente em que convive (SILVA et al., 2019).

Ao se compreender a resiliência humana como um processo, presume-se que existam fatores que contribuam para seu desenvolvimento, seja facilitando ou dificultando. Esses fatores são os de risco e os de proteção. Os fatores de risco são situações estressantes que induzem as pessoas ou grupo de pessoas às crises, colocando-as em condições de enfrentamento e respostas às dificuldades. Já os fatores de proteção são possíveis auxiliadores no enfrentamento dessas dificuldades (MARCHEZINI; FORINI, 2019).

Perim et al. (2015) descrevem cinco fatores como características essenciais da resiliência humana: autossuficiência, sentido de vida, equanimidade, perseverança e 
Aline Francilurdes Nery do Vale, Juliana Carvalho de Sousa, Agostinha Mafalda Barra de Oliveira, Suzana Virgínia da Costa Regis e Joyce Silva Soares de Lima

singularidade existencial. O fator autossuficiência representa a crença que o indivíduo tem em si mesmo em suas forças pessoais. Para Silva et al. (2019), esse fator compreende a capacidade de o indivíduo identificar seus limites e possiblidades.

O fator sentido de vida refere-se à percepção que o sujeito possui sobre o propósito da vida, acreditando que há um bom motivo para se viver (FELGUEIRAS; FESTAS; VIEIRA, 2010), sendo este motivo resultado do esforço e da contribuição de cada um (WAGNILD; YOUNG, 1993).

O fator equanimidade relaciona-se com a capacidade de flexibilidade que o indivíduo possui em encarar os diversos acontecimentos de sua vida (WAGNILD; YOUNG, 1993). Referese a uma vida equilibrada em que se é capaz de enfrentar as adversidades com senso de humor (FELGUEIRAS; FESTAS; VIEIRA, 2010), aceitando-as como um processo necessário, que deve ser encarado da melhor forma possível (PERIM et al., 2015).

O fator perseverança baseia-se na capacidade do indivíduo em não desanimar mesmo diante as dificuldades do dia a dia, mas prosseguir com determinação apesar dos percalços, estabelecendo metas e buscando realizá-las (WAGNILD, 2010).

Por último, o fator singularidade existencial é o sentimento que a pessoa possui de ser

livre e única. É também a consciência de que o caminho da vida de cada pessoa é único e há experiências que não devem ser compartilhadas com outros, mas enfrentadas sozinhas (WAGNILD; YOUNG, 1993).

\subsection{RESILIÊNCIA ORGANIZACIONAL}

Em uma visão micro, a compreensão do fenômeno da resiliência na organização é de extrema importância para que os gestores possam entender e realizar ações protetivas e preventivas à saúde dos colaboradores, pois a resiliência em contexto organizacional proporciona uma relação saudável entre o indivíduo e seu trabalho. A capacidade de ser resiliente é um diferencial para que os colaboradores se mantenham saudáveis e com desempenho adequado na organização (DEMO et al., 2019).

Por sua vez, em uma visão macro, a resiliência organizacional pode ser definida como a capacidade de uma organização desenvolver respostas situacionais para rupturas que representam ameaças potenciais à sobrevivência da organização. Também inclui o desenvolvimento de novas capacidades e expansão de habilidades, permitindo a exploração de oportunidades e a construção de competências para lidar com adversidades futuras (GOLDSCHMIDT; PAIVA; IRIGARAY, 2019). A resiliência é um comportamento estrategicamente importante para o sucesso, crescimento e mesmo sobrevivência da organização (ROOK et al., 2018).

Nesse contexto, Vasconcelos et al. (2015) sugeriram, com base em uma pesquisa realizada em uma empresa brasileira de energia, EBE S.A, que uma organização resiliente deve ser também uma organização inovadora e sustentável. Ou seja, que desenvolva políticas e práticas de gestão de pessoas capazes de fazer com que a organização responda com rapidez, eficiência e eficácia às inovações tecnológicas, organizacionais e sistêmicas, gerando assim, uma vantagem competitiva sustentável.

Em complemento, Beuren e Santos (2019), fundamentados em um estudo com empresas em processo de fusões e aquisições, inferiram que a capacidade de uma organização ser resiliente aumenta à medida que um controle coercitivo passa a ser mais presente, ou vice-versa. Os resultados dessa pesquisa reforçam ainda que a resiliência é um processo de desenvolvimento e não um resultado estático e que por isso, a organização precisa aprender constantemente, adaptar-se, auto organizar-se e agir antecipadamente. 
O impacto da COVID-19 mediado pela resiliência humana em microempreendores do ramo da beleza

Da mesma forma, Duchek (2020), por meio de evidências empíricas, reforça esses achados, de que resiliência organizacional é uma capacidade fundamental em processos de adaptações, tensões e inovações constantes, além de ser contribuir para sua vantagem competitiva sustentável. Em vistas disso, as organizações devem ter em seu quadro de gestores pessoas resilientes, que adotem medidas proativas e geram mudanças em seus negócios para lidar com as adversidades cotidianas (BEUREN; SANTOS; BERND, 2020).

\section{METODOLOGIA}

A pesquisa possui um caráter qualitativo, à medida que lida com o processo de compreensão de fenômenos, ancorando-se em análises do conteúdo discursado pelas entrevistadas, envolvendo "o universo dos significados, dos motivos, das aspirações, das crenças, dos valores e das atitudes" (MINAYO; DESLANDES; GOMES, 2016, p. 21). Ademais, vale destacar que a pesquisa possui uma tipologia descritiva. Denzin e Lincoln (2016) elencam que a pesquisa descritiva envolve a observação e análise dos achados da pesquisa sem interferência do pesquisador.

No que tange a técnica de coleta de dados, evocou-se a entrevista semiestruturada a fim de compreender os significados dados aos fenômenos levantados (GODOY, 2007). O roteiro de entrevista foi elaborado pelas autoras, com questões abertas que permitiram identificar os cinco fatores propostos por Perim et al. (2015) como características essenciais da resiliência humana. Quais sejam autossuficiência, sentido de vida, equanimidade, perseverança e singularidade existencial. Tais questões serão apresentadas na Análise e Discussão dos Resultados de cada um desses fatores.

A pesquisa ocorreu de modo virtual, por meio de mensagens de voz no aplicativo WhatsApp. Cada entrevista durou cerca de 40 minutos, e foram realizadas no mês de abril de 2020. A escolha do método deu-se em cumprimento a recomendação do isolamento social dada a pandemia da COVID-19. Além disso, Costa, Dias e Di Luccio (2009) evocam que as entrevistas virtuais são consideradas adequadas e satisfatórias à medida que o objetivo da pesquisa permite tal adequação.

Os sujeitos investigados foram dez microempreendedoras do ramo da beleza da cidade de Mossoró-RN. Optou-se por este segmento por entender que esse setor foi um dos mais afetados com a pandemia da COVID-19, apresentando uma perda de $69 \%$ no faturamento, de acordo com o SEBRAE (2020). As entrevistadas foram escolhidas pelos critérios de conveniência e bola-de-neve, e o seu quantitativo foi delineado pelo processo de saturação de dados (GLASER; STRAUSS, 2017).

Após transcrição dos áudios, para a compreensão dos relatos obtidos, foi utilizada a técnica da Análise de Núcleos de Sentido (ANS), adaptada por Mendes (2007) a partir da técnica de análise de conteúdo de Bardin (2015). Para Mendes (2007, p. 72) “a ANS consiste no desmembramento do texto em unidades, em núcleos de sentido formados a partir da investigação dos temas psicológicos sobressalentes do discurso".

\section{ANÁLISE E DISCUSSÃO DOS RESULTADOS}

O Quadro 1 traz a caracterização sociodemográfica das dez microempreendedoras individuais, que atuam no ramo de beleza em Mossoró, aceitaram participar desta pesquisa e responderam, por mensagens de áudio no WhatsApp, a entrevista. Para manter o anonimato das entrevistadas, elas serão tratadas aqui pelo número que corresponde à sequência em que foram entrevistadas. 
Aline Francilurdes Nery do Vale, Juliana Carvalho de Sousa, Agostinha Mafalda Barra de Oliveira, Suzana Virgínia da Costa Regis e Joyce Silva Soares de Lima

Quadro 1 - Caracterização das informantes da pesquisa realizada no final de março de 2020.

\begin{tabular}{|c|c|c|c|c|c|c|}
\hline Informante & $\begin{array}{c}\text { Idade } \\
\text { (anos) }\end{array}$ & $\begin{array}{c}\text { Estado } \\
\text { civil }\end{array}$ & Filhos & $\begin{array}{c}\text { Nível de } \\
\text { instrução }\end{array}$ & Especialidade & $\begin{array}{c}\text { Tempo de } \\
\text { serviço }\end{array}$ \\
\hline 1 & 42 & Casada & 2 filhos & $\begin{array}{c}\text { Superior } \\
\text { completo }\end{array}$ & $\begin{array}{c}\text { Esteticista, especialista em } \\
\text { bronzeamento natural }\end{array}$ & 8 anos \\
\hline 3 & 46 & Casada & 3 filhos & $\begin{array}{c}\text { Superior } \\
\text { incompleto }\end{array}$ & $\begin{array}{c}\text { Cabeleireira, especialista em } \\
\text { Alisamento }\end{array}$ & 18 anos \\
\hline 4 & 54 & Separada & 2 filhos & $\begin{array}{c}\text { Superior } \\
\text { completo }\end{array}$ & $\begin{array}{c}\text { Cabeleireira, especialista em } \\
\text { megahair }\end{array}$ & 21 anos \\
\hline 5 & 31 & Solteira & 2 filhos & $\begin{array}{c}\text { Ensino médio } \\
\text { completo }\end{array}$ & Cabeleira & 2 anos \\
\hline 7 & 26 & Casada & 3 filhos & $\begin{array}{c}\text { Ensino médio } \\
\text { completo }\end{array}$ & Designer de sobrancelhas & 2 anos \\
\hline 8 & 24 & Solteira & Nenhum & $\begin{array}{c}\text { Ensino médio } \\
\text { completo }\end{array}$ & $\begin{array}{c}\text { Micropigmentadora e } \\
\text { Designer de sobrancelhas }\end{array}$ & 4 anos \\
\hline 10 & 32 & Casada & 3 filhos & $\begin{array}{c}\text { Ensino médio } \\
\text { completo }\end{array}$ & $\begin{array}{c}\text { Esteticista e Designer de } \\
\text { sobrancelhas }\end{array}$ & 10 anos \\
\hline
\end{tabular}

Fonte: dados da pesquisa (2020).

Em relação às demais informações fornecidas nas entrevistas, optou-se por utilizálas de forma conjunta, através do enquadramento baseado nos cinco fatores descritos por Perim et al. (2015) como caracterizadores essenciais da resiliência humana: autossuficiência, sentido de vida, equanimidade, perseverança e singularidade existencial.

Quanto ao primeiro fator, de autossuficiência, observaram-se por meio das falas das informantes duas categorias: confiança em si, quando instigadas a responder se se sentem capazes de realizar seus sonhos; e erro como oportunidade de aprendizagem, quando questionadas sobre o que costumam fazer com os erros cometidos no passado.

No Quadro 2 estão as categorias identificadas com suas respectivas falas.

Quadro 2 - Categorias e falas relacionadas ao fator autossuficiência

\begin{tabular}{|l|l|}
\hline Categorias & \multicolumn{1}{c|}{ Falas } \\
\hline \multirow{3}{*}{$\begin{array}{l}\text { Confiança } \\
\text { em si }\end{array}$} & $\begin{array}{l}\text { Com certeza, com certeza é, eu sou capaz de conseguir. O que eu faço pra isso? Eu corro atrás, } \\
\text { eu não paro quando eu quero alguma coisa. [...] Mas, com certeza eu sou capaz porque eu não } \\
\text { fico parada. (Informações extraídas da Entrevistada 1) } \\
\text { Sim me sinto capaz sim, se tiver trabalho [...]. (Informações extraídas da Entrevistada 2) } \\
\text { Sim, com fé a gente vai longe. (Informações extraídas da Entrevistada 4) } \\
\text { Capaz mesmo, tem dias que não me sinto. Mas estou trabalhando para mim mesma e } \\
\text { acredito no meu potencial. (Informações extraídas da Entrevistada 7) } \\
\text { Sim, estou focando na organização financeira, administrando e investindo neles. Trazendo } \\
\text { mais clientes para mim, através do bom atendimento e da qualidade dos serviços. } \\
\text { (Informações extraídas da Entrevistada 8) } \\
\text { Sim, eu acredito sim que eu sou capaz de realizar tudo que eu sonhar, [...]. E eu acredito sim } \\
\text { que eu sou capaz de realizar tudo que eu sonho [...]. (Informações extraídas da Entrevistada } \\
\text { 9) }\end{array}$ \\
\hline
\end{tabular}


O impacto da COVID-19 mediado pela resiliência humana em microempreendores do ramo da beleza

\begin{tabular}{|c|l|}
\hline $\begin{array}{c}\text { Erro como } \\
\text { oportunidade } \\
\text { de } \\
\text { aprendizagem }\end{array}$ & $\begin{array}{l}\text { Aprendo um pouco e não cometo mais. Tudo nessa vida é aprendizado e com os erros que } \\
\text { aprendemos. (Informações extraídas da Entrevistada 1) } \\
\text { Eu procuro não cometer não cometer o mesmo erro novamente. Errar é preciso e é para } \\
\text { com nossos erros a gente aprender a não cometer os mesmos erros } \\
\text { novamente. (Informações extraídas da Entrevistada 2) } \\
\text { Tento não repetir, né? E... e reavaliar onde errei. (Informações extraídas da Entrevistada } \\
5) \\
\text { Eu supero, mas tento não está falando e nem repetindo né? E aí sigo a vida. Acho que tudo } \\
\text { é pra nos fortalecer, sejam acertos ou erros. (Informações extraídas da Entrevistada 7) } \\
\text { Aprendo com os erros, mas deixo no passado. (Informações extraídas da Entrevistada 8) }\end{array}$ \\
\hline
\end{tabular}

Fonte: dados da pesquisa (2020).

Por sua vez, em relação ao fator sentido de vida, emergiram das falas das entrevistas duas categorias: esforço próprio e satisfação com o trabalho. O Quatro 3 apresenta suas respectivas categorias e falas, quando questionadas a responder sobre o que fazem para realizar seus sonhos. As autoras Benítez-Corona e Barrón-Tirado (2018) reforçam que o pensamento crítico no olhar resiliente é considerado um fator protetor, pois permite ao indivíduo refletir sobre os ganhos que dão sentido à sua vida.

Quadro 3 - Categorias e falas relacionadas ao fator sentido de vida

\begin{tabular}{|c|c|}
\hline Categorias & Falas \\
\hline $\begin{array}{l}\text { Esforço } \\
\text { próprio }\end{array}$ & $\begin{array}{l}\text { O que eu faço pra isso? Eu corro atrás, eu não paro quando eu quero alguma coisa. [...] eu } \\
\text { tenho metas, eu tenho um sonho para aquele ano e eu coloco escrito, e quando eu vou } \\
\text { conseguindo realizar eu vou riscando, vou riscando, riscando [...] Aí a gente não para, os } \\
\text { sonhos não param. Aí eu corro atrás e busco, estudo, procuro ideias e invisto em cursos, } \\
\text { procuro melhorar pra que esse sonho seja realizado, pra que eu consiga realizá-lo. } \\
\text { (Informações extraídas da Entrevistada 1) } \\
\text { Com muito trabalho a gente consegue sim realizar nossos sonhos, sim, com muito esforço } \\
\text { também, né? Tem que se esforçar muito! (Informações extraídas da Entrevistada 2) } \\
\text { [...] levo meu trabalho muito, muito a sério. Me dedico, trabalho todos os dias. É realmente } \\
\text { isso, levando a sério realmente a minha profissão. Eu não gosto de viver no comodismo, gosto } \\
\text { sempre de batalhar pra conseguir algo a mais, porém um passo de cada vez, sem ambição, } \\
\text { sem ter que passar por cima de ninguém, entendeu? [...] E hoje em dia eu sou muito satisfeita } \\
\text { com o que eu já consegui, eu agradeço muito a Deus, eu sei é, que tudo que eu consegui um } \\
\text { dia, que hoje eu tenho, um dia atrás eu sonhei, e que de agora em diante eu terei outras } \\
\text { metas, outros sonhos mais pra frente, porque não tem graça se a gente parar de sonhar e lutar } \\
\text { pelo que a gente quer. (Informações extraídas da Entrevistada 9) }\end{array}$ \\
\hline $\begin{array}{l}\text { Satisfação } \\
\text { com } \\
\text { trabalho }\end{array}$ & $\begin{array}{l}\text { Sim, muito grata a Deus por minha profissão, pois amo o que faço. Eu tenho uma profissão } \\
\text { que é muito gratificante. Uma vez eu alisei um cabelo que quando eu terminei de alisar a } \\
\text { cliente olhou pra mim e disse: - Eliane deixa eu te dar um abraço, meu sonho era ter meu } \\
\text { cabelo desse jeito. Isso aí é muito gratificante, sabe? Você ver a felicidade no rosto da cliente! } \\
\text { Então, eu sou muito grata por isso, sabe? Sou muito grata a Deus pela profissão que eu tenho. } \\
\text { Eu amo o que eu faço, eu amo demais, eu sou realizada com a minha profissão. A que eu amo } \\
\text { pegar um cabelo assim bem crespo, sabe aqueles cabelinhos assim bem crespo e a cliente sair } \\
\text { com ele assim balançando! Ah, eu amo, eu amo ver a felicidade no rosto delas. (Informações } \\
\text { extraídas da Entrevistada 2) } \\
\text { Ah, trabalho sempre com autoestima, meu trabalho e super gratificante, porque não } \\
\text { coloco mega em minhas clientes mal. Meu trabalho... já curei depressão, levantei autoestima } \\
\text { delas, elas me devolvem em dobro o que faço. Sou grata pelo que escolhi, os olhos brilham } \\
\text { quando se veem no espelho e isso não tem preço. (Informações extraídas da Entrevistada 3) }\end{array}$ \\
\hline
\end{tabular}


Aline Francilurdes Nery do Vale, Juliana Carvalho de Sousa, Agostinha Mafalda Barra de Oliveira, Suzana Virgínia da Costa Regis e Joyce Silva Soares de Lima

\begin{tabular}{|l|l|}
\hline $\begin{array}{l}\text { Eu era vendedora em uma loja e saí pra trabalhar na estética e amo o que faço. (Informações } \\
\text { extraídas da Entrevistada 4) } \\
{[\ldots] \text { um dos fatores que realmente me fazem trabalhar com muita dedicação é realmente o }} \\
\text { fato de eu gostar muito do que eu faço, de eu amar o que eu faço. Então realmente tudo se } \\
\text { torna mais fácil, mais leve, porque pra mim não é nenhum sacrifício trabalhar, pra mim é muito } \\
\text { prazeroso trabalhar, então o trabalho vai me levar a tudo que eu realmente desejar. [...] eu } \\
\text { tenho um trabalho que eu amo. (Informações extraídas da Entrevistada 9) }\end{array}$
\end{tabular}

Fonte: dados da pesquisa (2020).

Já no que diz respeito ao fator equanimidade identificaram-se quatro categorias de respostas ao enfrentamento da adversidade atual pela qual as entrevistadas estão vivenciando com essa pandemia: proação, criação, adaptação e inércia. Essas categorias emergiram principalmente nas respostas às perguntas de: $O$ que você está fazendo para complementar a renda neste período de quarentena? Como você reage diante de um ambiente de pressão? O Quatro 4 explana o resultado dessa análise.

De modo semelhante, os autores Färber e Rosendahl (2018) consideram como um dos fatores da resiliência a aceitação de si e da vida, que se referem à adaptabilidade, flexibilidade e perspectiva equilibrada da vida. Acrescido a isso, os autores Goldschmidt, Paiva e Irigaray (2019) declaram que, além da adaptação, o conceito de enfrentamento está relacionado à resiliência, indicando que enfrentamento significa um conjunto de estratégias utilizadas pelos indivíduos para se adaptarem às situações adversas e estressantes.

Quadro 4-Categorias e falas relacionadas ao fator equanimidade

\begin{tabular}{|c|c|}
\hline Categorias & Falas \\
\hline Proação & $\begin{array}{l}\text { Desde que começou. Eu não lembro há quantos dias atrás, eu sei que o espaço ficou fechado } \\
\text { dez dias, quase dez dias. E depois disso, como o espaço é uma família, uma equipe, e essa equipe } \\
\text { em suas necessidades de sobrevivência em casa, então eu procurei uma pessoa, a pessoa } \\
\text { responsável aqui pelo município, que está à frente desse caso, desse problema do corona aqui } \\
\text { no município e pedi a ela uma orientação, o que é que eu teria que fazer se eu quisesse voltar } \\
\text { ou se eu não poderia voltar, e ela me deu todas as orientações que eu voltasse a trabalhar [...]. } \\
\text { [...] quando eu vi que o movimento caiu muito, porque as pessoas não querem sair de casa pra } \\
\text { vim pra... por causa do corona, né? Não querem... Querem ficar no seu isolamento, é, eu vi o } \\
\text { movimento caindo e as despesas estavam lá, né? Despesas fixas, como água, luz, internet. E eu } \\
\text { tinha que resolver ou fazer algo pra que entrasse de outra maneira o fluxo no caixa, e eu } \\
\text { comecei a olhar pela internet, pesquisar e fui vendo e vi que eu podia é [...] (Informações } \\
\text { extraídas da Entrevistada 1) }\end{array}$ \\
\hline Criação & $\begin{array}{l}\text { Além de serviços que está sendo pouco, mas eu estou trabalhando. É... pra minhas clientes que } \\
\text { não querem sair de casa, eu fiz kits de banho de lua, que é um serviço que eu ofereço aqui no } \\
\text { espaço pra cliente fazer no conforto da sua casa.[...] Então eu peguei meus produtos } \\
\text { profissionais e dividi, fiz em porções que dê pra uma cliente para que ela faça no conforto do } \\
\text { seu lar, com o mesmo procedimento profissional ela vai comprar o kit por um preço menor, com } \\
\text { produtos de primeira qualidade, mas ela vai fazer no conforto da casa dela. [...] Eu já tô tentando } \\
\text { fazer outra coisa também que eu faço aqui no espaço, montar alguma coisa pra cliente também } \\
\text { fazer em casa, mas eu tô vendo pelo menos os custos, se isso é bom pra mim, se vai valer a pena, } \\
\text { porque os valores dos produtos de banho de lua, eu calculando tudo pra poder fazer, eu vi que } \\
\text { dava bom, dava legal, eu ia conseguir tirar um lucro bom. Mas já os outros produtos que eu vejo } \\
\text { como, vamos dizer assim, uma limpeza de pele... Os produtos de limpeza de pele são muito } \\
\text { caros, e então eu tô vendo se vale a pena, se não valer a pena eu vou procurar outro meio, e } \\
\text { assim eu vou pensando e buscando solucionar aquele problema que eu tenho na minha frente. } \\
\text { E outra coisa que eu esqueci de mencionar aí o que eu fiz, né, nessa crise, outra ideia bacana, } \\
\text { eu lancei } 15 \text { vouchers, } 15 \text { cupons de desconto, tipo assim, lancei } 15 \text { e você comprava um bronze } \\
\text { e você ganhava outro pra você fazer quando você quisesse depois da pandemia. Mas aí foi uma } \\
\text { promoção relâmpago! Lancei } 15 \text {, você tem que vir, comprar, pagar e ganhar, entendeu? Não } \\
\text { podia pagar depois, não podia deixar pra depois, tinha que ser àquela hora, e foi um sucesso! }\end{array}$ \\
\hline
\end{tabular}


O impacto da COVID-19 mediado pela resiliência humana em microempreendores do ramo da beleza

\begin{tabular}{|c|c|}
\hline & $\begin{array}{l}\text { Eu lancei de onze horas do dia e de quatro horas da tarde não tinha mais nem um voucher. E foi } \\
\text { uma maneira de o dinheiro... de eu ver... de o dinheiro entrar mais. (Informações extraídas da } \\
\text { Entrevistada 1) }\end{array}$ \\
\hline Adaptação & 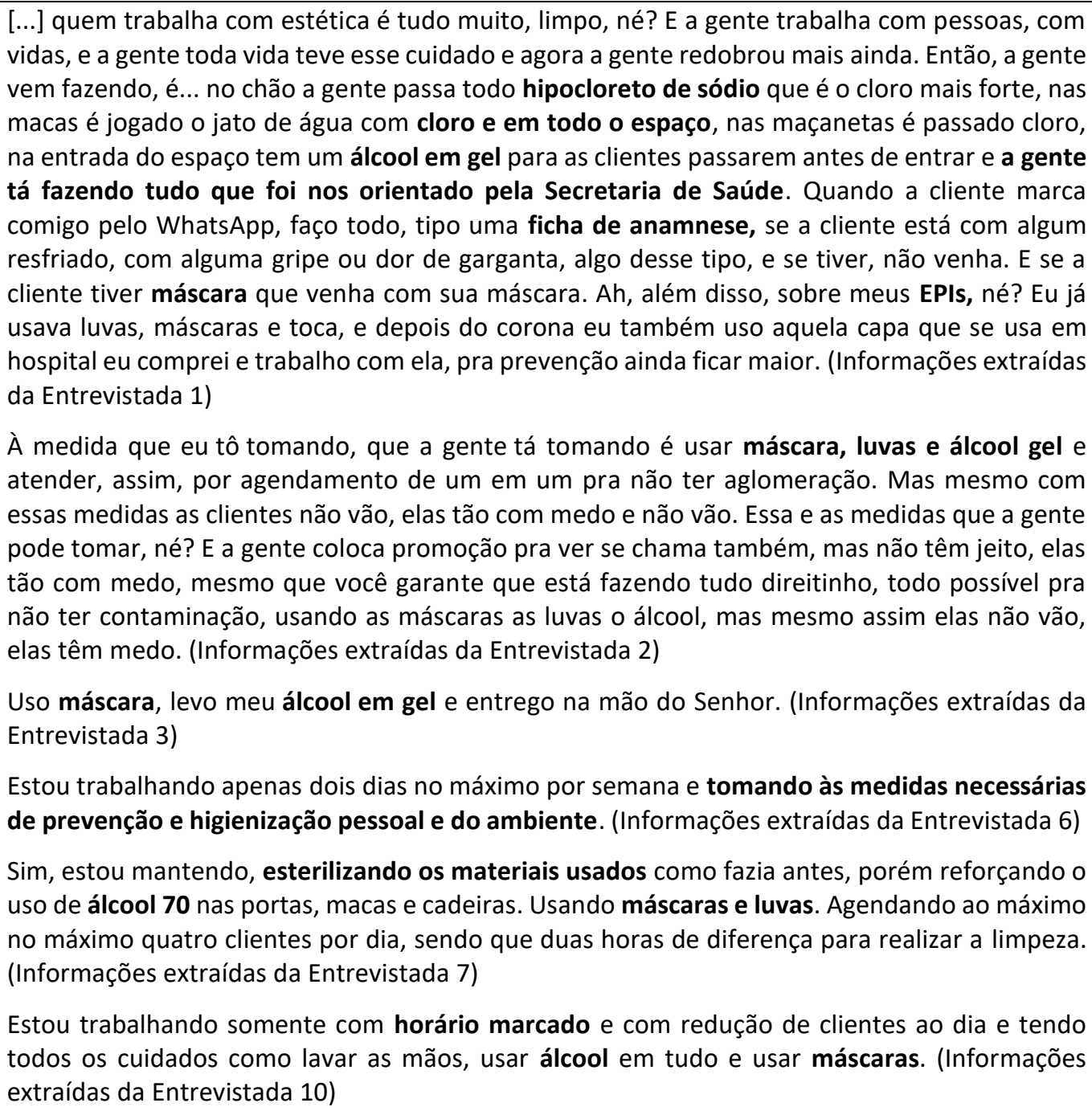 \\
\hline Inércia & $\begin{array}{l}\text { Agora no momento não estou fazendo nada, porque não tem o que fazer, sabe? Se você } \\
\text { procurar outra coisa pra fazer, não tem! Tudo fechado! Não tem! Então agora no momento } \\
\text { eu tô só dependendo do meu marido. O que é péssimo para mim, porque sou muito } \\
\text { independente. (Informações extraídas da Entrevistada 2) } \\
\text { Bom, se surgir serviço, eu procuro fazer a domicílio, porque se todo mundo tiver isolado, não } \\
\text { há perigo! (Informações extraídas da Entrevistada 3) } \\
\text { Por enquanto nenhum no salão. Estou só trabalhando na venda de manutenção a ponta } \\
\text { entrega. (Informações extraídas da Entrevistada 5) } \\
\text { Nada! (Informações extraídas da Entrevistada 6) } \\
\text { Não estou fazendo nada. (Informações extraídas da Entrevistada 10) }\end{array}$ \\
\hline
\end{tabular}

Fonte: dados da pesquisa (2020).

Quanto ao fator perseverança, extraíram-se três categorias: busca de informação, planejamento e determinação, com base principalmente nas respostas das seguintes perguntas: O que você faz para realizar seus sonhos? Quais as suas perspectivas na profissão? Você costuma cumprir os planos traçados? O Quadro 5 apresenta as três categorias identificadas e suas respectivas falas. 
Aline Francilurdes Nery do Vale, Juliana Carvalho de Sousa, Agostinha Mafalda Barra de Oliveira, Suzana Virgínia da Costa Regis e Joyce Silva Soares de Lima

Semelhante a esse achado, os autores Blanco et al. (2018) afirmam que esse fator se refere à clareza que as pessoas possuem sobre seus objetivos e ao esforço que realizam para atingir esses objetivos. Além disso, os autores Magnano, Craparo e Paolillo (2016) declaram que a resiliência representa um fator central de motivação, perseverança e persistência, aumentando as probabilidades de sucesso e realização dos objetivos, considerando o fator inteligência emocional, ou seja, utilização de emoções positivas em proveito próprio, um prérequisito para se tornar resiliente.

Quadro 5 - Categorias e falas relacionadas ao fator perseverança

\begin{tabular}{|c|c|}
\hline Categorias & Falas \\
\hline $\begin{array}{l}\text { Busca de } \\
\text { informações }\end{array}$ & $\begin{array}{l}\text { [...] eu corro atrás e busco, estudo, procuro ideias e invisto em cursos, procuro melhorar } \\
\text { para que esse sonho seja realizado, pra que eu consiga realizá-lo. (Informações extraídas } \\
\text { da Entrevistada 1) } \\
\text { [...] todo ano faço cursos, vou a Workshops. E estou sempre antenada nas inovações. } \\
\text { (Informações extraídas da Entrevistada 3) } \\
\text { Faço cursos, procuro me aperfeiçoar, melhorou nos atendimentos, materiais e técnicas. } \\
\text { (Informações extraídas da Entrevistada 7) }\end{array}$ \\
\hline Planejamento & $\begin{array}{l}\text { [...] Como eu disse a você lá no começo, eu tenho metas, eu tenho um sonho para aquele } \\
\text { ano e eu coloco escrito, e quando eu vou conseguindo realizar eu vou riscando, vou } \\
\text { riscando, riscando [...] aí Deus vem e coloca outro sonho no coração da gente, né? } \\
\text { (Informações extraídas da Entrevistada 1) } \\
\text { Traço metas e ponho em prática. (Informações extraídas da Entrevistada 4) } \\
\text { Sim... estabeleço metas e luto. (Informações extraídas da Entrevistada 6) } \\
\text { Eu sempre planejo. (Informações extraídas da Entrevistada 10) }\end{array}$ \\
\hline Determinação & $\begin{array}{l}\text { [...] Eu corro atrás, eu não paro quando eu quero alguma coisa. [...] Eu gosto muito de criar, } \\
\text { eu gosto muito de inventar, eu sou elétrica, não fico parada! Acho que quem me } \\
\text { acompanha, vê! [...] Minhas campanhas chamam atenção tanto na cidade como fora da } \\
\text { cidade, quando eu lanço minhas campanhas, as ideias vão até pra outros Estados. Vários } \\
\text { espaços de bronzeamento vêm pra mim e pede autorização pra usar a imagem das minhas } \\
\text { campanhas. Então são campanhas, assim, que repercutem muito, porque eu invisto em } \\
\text { rádio, panfletos, mídias digitais com fotos de modelos, lanço campanha com outros } \\
\text { patrocinadores, com sorteios de brindes. (Informações extraídas da Entrevistada 1) } \\
\text { Com muito trabalho a gente consegue sim realizar nossos sonhos, sim, com muito esforço } \\
\text { também, né? Tem que se esforçar muito! (Informações extraídas da Entrevistada 2) } \\
\text { Sim! Estou sempre buscando o melhor e tento não me abalar em meio ao caos. [...] Creio } \\
\text { que quando tudo isso passar, boa parte dos meus planos botarei em prática. [...] Sim, com } \\
\text { fé a gente vai longe. (Informações extraídas da Entrevistada 4) } \\
\text { Sim... estabeleço metas e luto. (Informações extraídas da Entrevistada 6) } \\
\text { [...] E se eu traçar um plano, eu cumpro, posso não cumprir no tempo correto, mas } \\
\text { cumpro! (Informações extraídas da Entrevistada 7) }\end{array}$ \\
\hline
\end{tabular}

Fonte: dados da pesquisa (2020).

Por fim, em relação ao quinto e último fator, singularidade existencial, identificaramse duas categorias: independência compartilhada e dependência. Tais categorias foram identificadas nas respostas para as perguntas: Você acredita que precisa da ajuda das pessoas para alcançar os seus objetivos ou que sozinha você alcançará tudo que deseja? Como você reage quando está com problemas?

Confirmando os achados na categoria dependência, para as autoras Benítez-Corona e Barrón-Tirado (2018), os processos de interações são primordiais para o desenvolvimento 
O impacto da COVID-19 mediado pela resiliência humana em microempreendores do ramo da beleza

da resiliência, pois um indivíduo só consegue se desenvolver tecendo com outro. No entanto, os autores Silva Júnior et al. (2019) apontaram que não foi encontrada correlação entre suporte social e os índices de resiliência, ou seja, o suporte social não se mostrou um fator preditivo para as variações da capacidade de resiliência da população pesquisada.

Quadro 6 - Categorias e falas relacionadas ao fator singularidade existencial

\begin{tabular}{|c|c|}
\hline Categorias & Falas \\
\hline $\begin{array}{l}\text { Independência } \\
\text { compartilhada }\end{array}$ & $\begin{array}{l}\text { Na verdade, quando eu estou com problema eu fico calada, pensativa, aí penso, penso, } \\
\text { penso em como resolver, e às vezes eu perco o sono até a madrugada, porque eu quero } \\
\text { resolver aquele [...] Eu nem sou de estar chorando por aquele problema, claro que eu } \\
\text { fico pensativa, penso, penso, às vezes me pergunto por que, mas bem rápido deixo } \\
\text { passar e digo: eu tenho agora que dá uma solução nesse problema! E como a pensar, } \\
\text { pensar, e busco a Deus que é o que me dá sabedoria, e eu peço a ele: Senhor me dá } \\
\text { sabedoria e me dá alguma ideia para eu resolver a este problema. [...] A gente não faz } \\
\text { nada sozinho, não consegue, né? Nós precisamos trabalhar em conjunto, eu tenho uma } \\
\text { equipe no meu espaço que eu preciso da ajuda delas porque ele não funciona comigo } \\
\text { sozinha, eu preciso de outras pessoas para me ajudar e eu também ajudar elas. Preciso } \\
\text { também das clientes porque sem clientes a gente também não trabalha, e eu acredito } \\
\text { que isso é uma troca de experiência entre cliente e profissional. (Informações extraídas } \\
\text { da Entrevistada 1) } \\
\text { De ajuda todos nós precisamos, mas também tenho condições de me virar só [...]. Não } \\
\text { guardo porque sou do tipo que resolvo os problemas logo sem guardar. Abro meu } \\
\text { coração pra as pessoas certas e fico leve. (Informações extraídas da Entrevistada 3) } \\
\text { Sim, é sempre bom contar com alguém uma ajuda é sempre bem-vinda. [...] } \\
\text { Primeiramente com Deus e depois procuro alguém que possa me ouvir e me ajudar com } \\
\text { palavras sábias. (Informações extraídas da Entrevistada 4) } \\
\text { Depende! Objetivo? Precisamos das clientes, como as clientes também precisam de nós. } \\
\text { Se trabalharmos com ética e responsabilidade, alcançaremos nossos objetivos, seja com } \\
\text { ou sem ajuda. (Informações extraídas da Entrevistada 5) } \\
\text { Com ajuda, embora não ajudem, né? (Informações extraídas da Entrevistada 6) } \\
\text { Sim, converso com pessoas de confiança da minha família, mas com certeza será fruto } \\
\text { de um trabalho individual. (Informações extraídas da Entrevistada 8) }\end{array}$ \\
\hline Dependência & $\begin{array}{l}\text { Preciso sim. Familiares e parceiros da área. Sozinhos não chegamos a lugar algum. [...] } \\
\text { Antes eu costumava desabafar, hoje não tanto. Eu guardo muito, principalmente quando } \\
\text { é financeiro, sendo que sempre após eu tenho crise de ansiedade. Mas tento resolver e } \\
\text { não me lastimar. (Informações extraídas da Entrevistada 7) } \\
\text { Eu não sei se eu iria conseguir sozinha, mas tudo que eu consegui até hoje não foi só. É, } \\
\text { principalmente com a ajuda do meu esposo que sempre me apoiou, meus familiares } \\
\text { mais próximos, minha mãe, minha sogra, então, eu não sei se eu iria conseguir só, mas } \\
\text { tudo que eu consegui até hoje foram com ajuda deles também. [...] não, eu não encaro } \\
\text { tudo só não. Eu sempre desabafo e sempre é com meu esposo, porque ele é meu parceiro } \\
\text { em tudo, não só como esposo, mas na minha vida financeira também, na minha vida } \\
\text { profissional, ele está sempre comigo. (Informações extraídas da Entrevistada 9) }\end{array}$ \\
\hline
\end{tabular}

Fonte: dados da pesquisa (2020).

Como síntese, a Figura 1 evidencia as principais categorias emergidas nos discursos das entrevistadas para cada um dos fatores propostos por Perim et al. (2015), que compõem o constructo de resiliência humana adotado neste trabalho. 
Aline Francilurdes Nery do Vale, Juliana Carvalho de Sousa, Agostinha Mafalda Barra de Oliveira, Suzana Virgínia da Costa Regis e Joyce Silva Soares de Lima

Figura 1: Síntese das categorias com base dos achados da pesquisa.

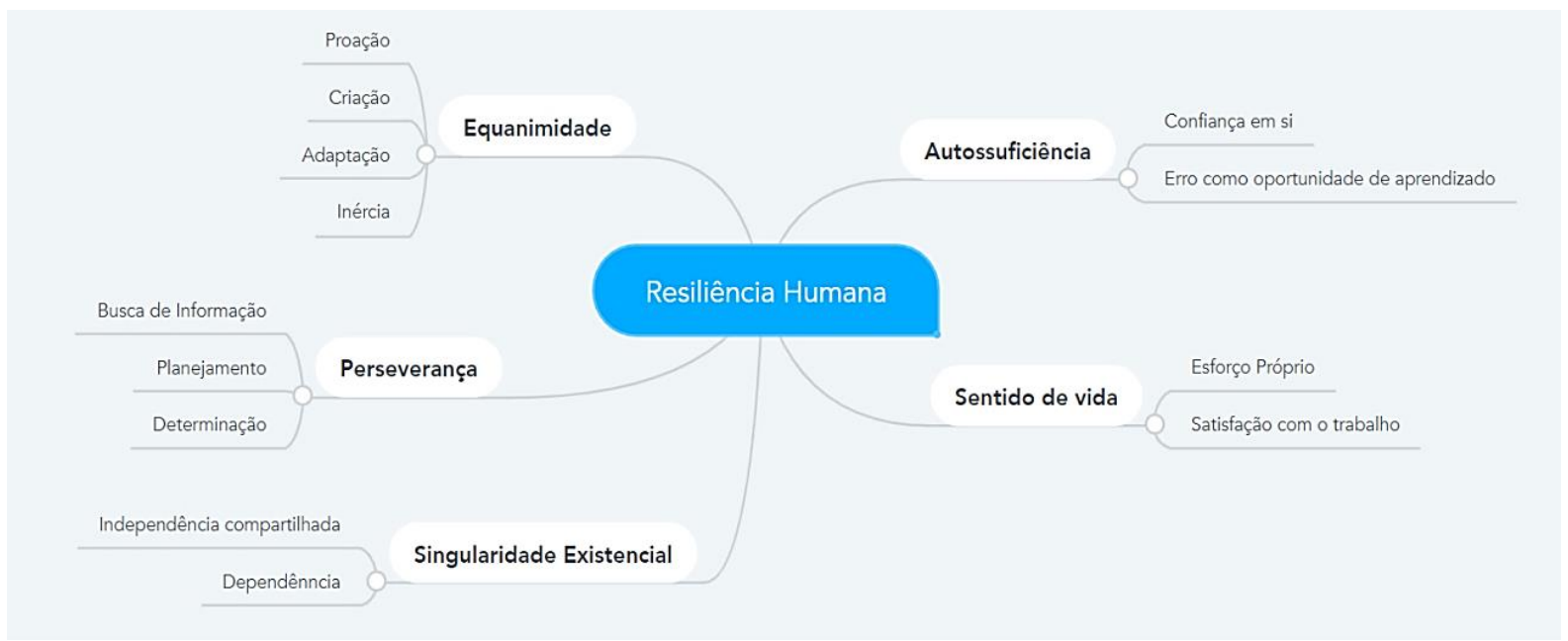

Fonte: dados da pesquisa (2020).

A fim de atender ao objetivo proposto de analisar o grau de resiliência dos microempreendedores individuais que atuam no ramo da beleza durante a pandemia da COVID-19, analisou-se cada informante em separado de acordo com as categorias identificadas em cada um dos fatores de resiliência. No Quadro 7, um resumo dessa análise possibilitou o alcance do objetivo proposto. Salienta-se que as palavras sublinhadas têm um sentido contrário ao conceito de resiliência.

Quadro 7 - Síntese das categorias por fator emergidas pelos sujeitos

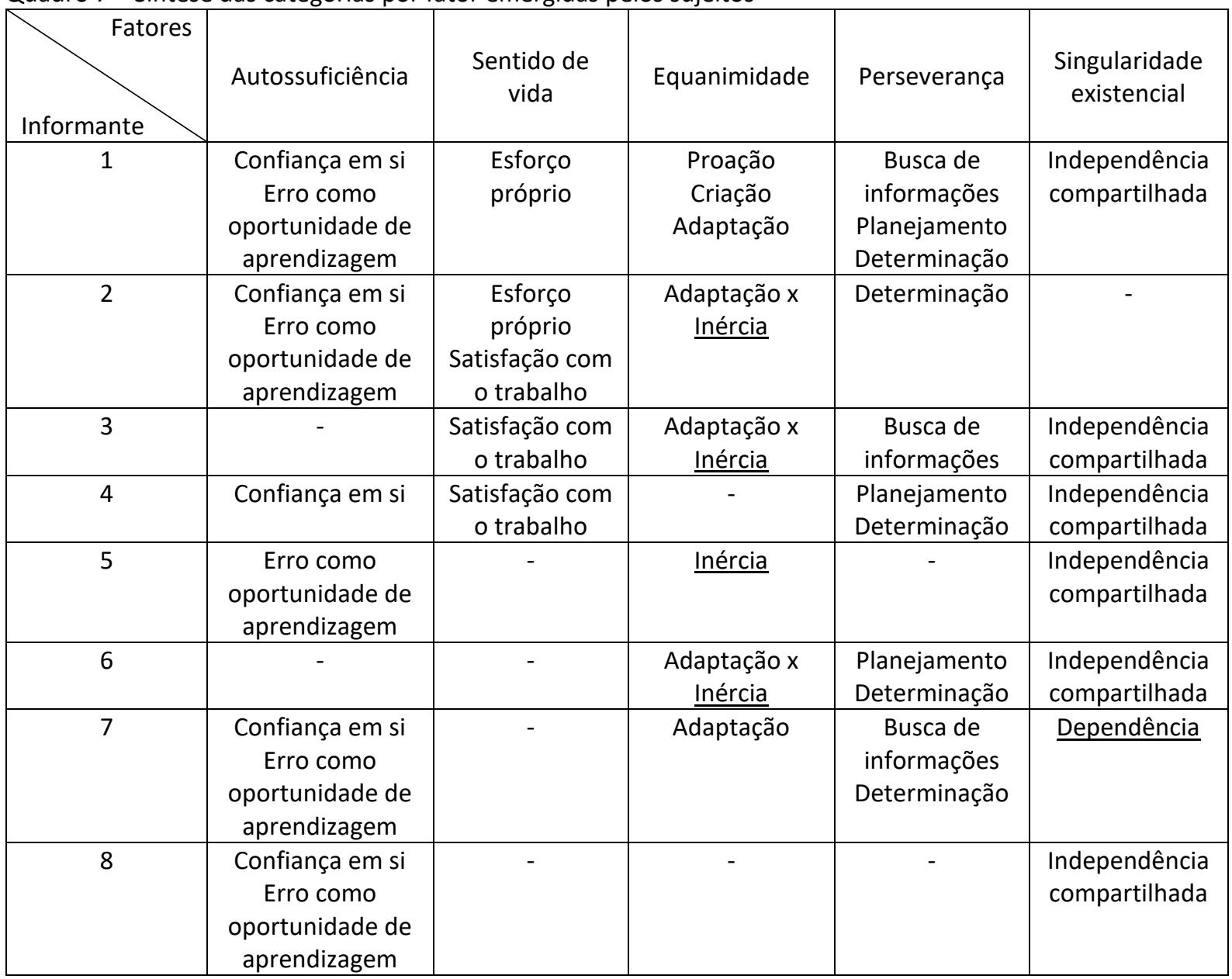


O impacto da COVID-19 mediado pela resiliência humana em microempreendores do ramo da beleza

\begin{tabular}{|c|c|c|c|c|c|}
\hline 9 & Confiança em si & $\begin{array}{c}\text { Esforço } \\
\text { próprio } \\
\text { Satisfação com } \\
\text { o trabalho }\end{array}$ & - & Dependência \\
\hline 10 & - & - & $\begin{array}{c}\text { Adaptação x } \\
\text { Inércia }\end{array}$ & Planejamento & - \\
\hline
\end{tabular}

Fonte: dados da pesquisa (2020).

Com base nos dados apresentados no Quadro 7, denota-se que apenas a Entrevistada 1 apresenta alto grau de resiliência, considerando que ela demonstrou, por meio de sua fala, os cinco fatores de resiliência, inclusive enquadrando-se em categorias únicas de Proação e Criação. Na sequência decrescente, a Entrevistada 4 aparece com quatro dos cinco fatores de resiliência, da mesma forma que as Entrevistadas 2 e 3 . Contudo, essas duas últimas apresentam uma ressalva pela categoria de Inércia, o que as colocam no mesmo patamar da Entrevista 7, que atende a três dos cinco fatores de resiliência. Por último, as Entrevistadas 5, $6,8,9$ e 10 só demonstram possuir dois dos cinco fatores de resiliência.

\section{CONSIDERAÇÕES FINAIS}

Os dados revelaram a manifestação de categorias de análise que se enquadram nas cinco dimensões elencadas por Perim et al. (2015). A autossuficiência, percepção de crença em si mesmo, trouxe categorias que envolvem a confiança em si próprio e a aprendizagem a partir do erro, sendo encarado, portanto, como uma oportunidade. Sentido de vida traz a satisfação com o labor, sentimento de realização profissional e o esforço demandado para alcance dos sonhos, como categorias que elevam o significado existencial. Quanto à equanimidade, também entendida como sensação de equilíbrio, evidencia um elemento possuidor de sentido contrário e inverso àqueles que conduzem a resiliência humana, como é o caso da inércia, ou seja, a ausência de atitudes mediante situações que exigiriam comportamentos ativos. Porém, ainda dentro do enquadramento da equanimidade, destacam-se categorias reveladoras da resiliência, como comportamentos caracterizados por proatividade, criatividade e adaptabilidade ao meio.

Acerca da perseverança, ato de lutar, buscar e focar nos objetivos, os achados revelam categorias que envolvem o processo de planejamento, coleta de informação (passo primordial no processo de planejar) e determinação para executar as ideias delimitadas. Por fim, tem-se a dimensão singularidade existencial, sentimento de unicidade, que fez emergir a categoria independência compartilhada, quando se é capaz de conseguir o que é delimitado, porém, o partilho com terceiros faz-se importante. Além disso, essa dimensão também faz surgir uma categoria oposta a resiliência humana, como a dependência de outros, o que vai de encontro com o sentimento de ser singular, e acreditar de modo pleno em suas capacidades.

No que tange o nível de resiliência humana dos sujeitos entrevistados, tem-se que apenas as entrevistadas 1 e 4 enquadram-se na categoria de alta resiliência. Por conseguinte, tem as entrevistadas 2, 3 e 7 revelando níveis moderados de resiliência e as entrevistadas 5, 6, 8, 9 e 10 demonstrando baixo grau de resiliência humana.

Os dados possuem relevância gerencial, à medida que as organizações precisam incorporar em seu quadro indivíduos resilientes, além de induzir o processo transformador para a incorporação/busca pela resiliência, ao passo que tal característica pode fazer com que alguns indivíduos consigam passar por momentos adversos de forma mais sábia e menos dolorosa, abrindo possibilidades para emergir a criatividade e a inovação, processos indutores 
Aline Francilurdes Nery do Vale, Juliana Carvalho de Sousa, Agostinha Mafalda Barra de Oliveira, Suzana Virgínia da Costa Regis e Joyce Silva Soares de Lima

da competitividade e sucesso organizacional. Por fim, tem-se a relevância acadêmica da pesquisa, dada a atualidade da temática e a escassez de estudos sobre a COVID-19 tendo como enfoque o parâmetro organizacional. Assim sendo, este estudo poderá trazer importantes ganhos para o conhecimento científico.

As limitações da pesquisa concentraram-se na velocidade da coleta, dada a imprevisibilidade da duração da quarentena, e a necessidade desta coleta ocorrer dentro dessa realidade temporal. Acerca das sugestões para trabalhos futuros, indica-se que as pesquisas devem se expandir a fim de buscar resultados generalistas, sendo necessário utilizar técnicas quantitativas. Além disso, há possibilidades de replicação da pesquisa em outros setores que estão sofrendo com o decreto de isolamento social por conta da pandemia, como o setor da moda, turismo, promoção de festa, dentre outros.

\section{REFERÊNCIAS}

AGÊNCIA SEBRAE DE NOTÍCIAS. Serviços de beleza está entre os segmentos mais atingidos. Disponível em: http://www.agenciasebrae.com.br/sites/asn/uf/NA/servicos-de-beleza-estaentre-os-segmentos-mais-atingidos,68e0e3c4e78f0710VgnVCM1000004c00210aRCRD Acesso em: 16 abr. 2020.

AL-AWADHI, A. M.; AL-SAIFI, K.; AL-AWADHI, A.; ALHAMADI, S. Death and contagious infectious diseases: Impact of the Covid-19 virus on stock market returns. Journal of Behavioral and Experimental Finance, v. 27, n. 100326, p. 1-14, 2020. DOI: https://doi.org/10.1016/j.jbef.2020.100326.

BARDIN, L. Análise de Conteúdo. São Paulo: Edições 70, 2015.

BENÍTEZ-CORONA, L.; BARRÓN-TIRADO, M. C. Análisis cualitativo de resiliencia en estudiantes de posgrado. Revista Electrónica Educare, Heredia, Costa Rica, v. 22, n. 1, p. 121, 2018. DOI: http://dx.doi.org/10.15359/ree.22-1.7.

BEUREN, I. M.; SANTOS, V.; BERND, D. C. Efeitos do sistema de controle gerencial no empowerment e na resiliência organizacional. BBR - Brazilian Business Review, Vitória, v. 17, n. 2, p. 211-232, 2020. DOI: https://doi.org/10.15728/bbr.2020.17.2.5.

BEUREN, I. M.; SANTOS, V. Sistemas de controle gerencial habilitantes e coercitivos e resiliência organizacional. Revista Contabilidade e Finanças, São Paulo, v. 30, n. 81, p. 307323, 2019. DOI: https://doi.org/10.1590/1808-057x201908210.

BEUTEL, M. E.; TIBUBOS, A. N.; KLEIN, E. M.; SCHMUTZER, G.; REINER, I.; KOCALEVENT, R.; BRÄHLER, E. Childhood adversities and distress - The role of resilience in a representative sample. PLOS ONE, Leipzig, Germany, v. 12, n. 3, p. 1-14, 2017. DOI: https://doi.org/10.1371/journal.pone.0173826.

BLANCO, J. R.; JURADO, P. J.; AGUIRRE, S. I.; AGUIRRE, J. F. Composición factorial de la Escala de Resiliencia Mexicana en universitarios mexicanos. Formación Universitaria, La Serena, México, v. 11, n. 6, p. 99-106, 2018. DOI: http://dx.doi.org/10.4067/S071850062018000600099. 
O impacto da COVID-19 mediado pela resiliência humana em microempreendores do ramo da beleza

COSTA, A. M. N.; DIAS, D. R.; DI LUCCIO, F. Uso de entrevistas on-line no método de explicitação do discurso subjacente (MEDS). Psicologia: Reflexão Crítica, Porto Alegre, v. 22 n. 1, p. 36-43, 2009. DOI: https://doi.org/10.1590/S0102-79722009000100006.

CRAVEN, M.; LIU, L.; MYSORE, M.; WILSON, M. Covid-19: Briefing note. Our latest perspectives on the coronavirus pandemic. McKinsey \& Company, v. 30, p. 1-21, 2020. DOI: https://doi.org/10.1007/s10479-020-03640-6.

CRUZ, E. J. E. R. SOUZA, N. V. D. O.; AMORIM, L. K. A.; PIRES, A. S.; GONÇALVES, F. G. A.; CUNHA, L. P. Resiliência como objeto de estudo da saúde do trabalhador: uma revisão narrativa. Revista de Pesquisa: Cuidado é Fundamental Online, Rio de Janeiro, v. 10, n.1, p. 283-288, jan./mar., 2018. DOI: https://doi.org/10.9789/2175-5361.2018.v10i1.283-288.

DEMO, G. FENELON, L.; COSTA, A. C.; WATANABE, E. Práticas de envolvimento produzem colaboradores resilientes? Mediação da identidade organizacional. Revista de Administração FACES Journal, Belo Horizonte, v. 18, n. 3, p. 27-43, jul./set., 2019. DOI: https://doi.org/10.21714/1984-6975FACES2019V18N3ART6472.

DENZIN, N. K.; LINCOLN, Y.S. Handbook of qualitative research. London: Sage, 2016.

DUCHEK, S. Organizational resilience: A capability-based conceptualization. Business Research, v. 13, n. 1, p. 215-246, 2020. DOI: https://doi.org/10.1007/s40685-019-0085-7.

FÄRBER, F.; ROSENDAHL, J. The association between resilience and mental health in the somatically III: a systematic review and meta-analysis. Deutsches Ärzteblatt International, v. 115, n. 38, 2018, p. 621, 2018. DOI: https://doi.org/10.3238/arztebl.2018.0621.

FELGUEIRAS, M. C.; FESTAS, C.; VIEIRA, M. Adaptação e validação da Resilience Scale de Wagnild e Young para a cultura portuguesa. Cadernos de Saúde, Lisboa, Portugal, v. 3, n. 1, p. 73-80, 2010. DOI: http://hdl.handle.net/10400.14/10934.

GLASER, B. G.; STRAUSS, A. L. The discovery of Grounded Theory: strategies for qualitative research. New York: Routledge, 2017.

GODOY, A. S. Estudo de caso qualitativo. In. GODOI, C. K.; BANDEIRA-DE-MELO, R.; SILVA, A. B. da (Orgs.). Pesquisa qualitativa em estudos organizacionais: paradigmas, estratégias e métodos. São Paulo: Saraiva, p. 115-146, 2007.

GOLDSCHMIDT, C. C.; PAIVA, K. C. M.; IRIGARAY, H. A. R. Organisational resilience: a proposal of an integrated model and research agenda. Tourism \& Management Studies, v. 15, n. 3, p. 37-46, 2019. DOI: http://dx.doi.org/10.18089/tms.2019.150304.

HORNOR, G. Resilience. Journal of Pediatric Health Care, v 31, n. 3, p. 384-390, 2016. DOI: https://doi.org/10.1016/j.pedhc.2016.09.005.

INSTITUTO BRASILEIRO DE GEOGRAFIA E ESTATÍSTICA - IBGE. Cidades. 2020. Disponível em: https://cidades.ibge.gov.br/brasil/rn/mossoro/panorama. Acesso em: 13 abr. 2020. 
Aline Francilurdes Nery do Vale, Juliana Carvalho de Sousa, Agostinha Mafalda Barra de Oliveira, Suzana Virgínia da Costa Regis e Joyce Silva Soares de Lima

INSTITUTO BRASILEIRO DE GEOGRAFIA E ESTATÍ́STICA - IBGE. Síntese de Indicadores Sociais. uma análise das condições de vida da População Brasileira, 2019. Disponível em: https://biblioteca.ibge.gov.br/index.php/bibliotecacatalogo?view=detalhes\&id=2101678. Acesso em: 13 de abr. 2020.

IRIGARAY, H. A. R.; PAIVA, K. C. M.; GOLDSCHMIDT, C. C. Resiliência organizacional: proposição de modelo integrado e agenda de pesquisa. Cadernos EBAPE, Rio de Janeiro, v. 15, n. esp., p. 390-408, 2017. DOI: http://dx.doi.org/10.1590/1679-395158881.

KAMLOT, D. Resiliência organizacional e marketing social: uma avaliação de fundamentos e afinidades. Cadernos EBAPE, Rio de Janeiro, v. 15, n. esp., p. 482-495, 2017. DOI: http://dx.doi.org/10.1590/1679-395160269.

KONRADT, C. E.; CARDOSO, T. A.; MONDIN, T. C.; SOUZA, L. D. M.; KAPCZINSKI, F.; SILVA, R. A. S.; JANSEN, K. Impact of resilience on the improvement of depressive symptoms after cognitive therapies for depression in a sample of young adults. Trends in Psychiatry and Psychotherapy, Porto Alegre, v. 40, n. 3, p. 226-231, 2018. DOI:

http://dx.doi.org/10.1590/2237-6089-2017-0047.

LIU, H.; ZHANG, C.; JI, Y.; YANG, L. Biological and psychological perspectives of resilience: is it possible to improve stress resistance? Frontiers in Human Neuroscience, n. 21, v. 12, p. 326, 2018. DOI: https://doi.org/10.3389/fnhum.2018.00326.

MAGNANO, P.; CRAPARO, G.; PAOLILLO, A. Resilience and emotional intelligence: which role in achievement motivation. International Journal of Psychological Research, Medellin, Columbia, v. 9, n. 1, p. 9-20, 2016. DOI: https://doi.org/10.21500/20112084.2096.

MARCHEZINI, V.; FORINI, H. A. Dimensões sociais da resiliência a desastres. REDES-Revista do Desenvolvimento Regional, Santa Cruz do Sul, v. 24, n. 2, p. 9-28, 2019. DOI:

DOI: http://dx.doi.org/10.17058/redes.v24i2.13000.

MENDES, A. M. B. Psicodinâmica do trabalho: Teoria, método e pesquisas. São Paulo: Casa do Psicólogo, 2007.

MINAYO, M. C. S.; DESLANDES, S.; GOMES, R. Pesquisa social: teoria, método criatividade. Petrópolis: Vozes, 2016.

MOLINA, T. J. S.; SANTO, D. E. S.; PAVÓN, M. J. M. Profesor universitario, ser en resiliencia: una mirada a su labor en el contexto educativo actual. Diálogos sobre Educación, Zapopan, México, v. 10, n. 19, p. 1-20, 2019. DOI: https://doi.org/10.32870/dse.v0i19.539.

MORETE, M. C.; SOLANO, J. P. C.; BOFF, M. S.; FILHO, W. J.; ASHMAWI, H. A. Resilience, depression, and quality of life in elderly individuals with chronic pain followed up in an outpatient clinic in the city of São Paulo, Brazil. Journal of Pain Research, v. 11, p. 25612566, 2018. DOI https://doi.org/10.2147/JPR.S166625. 
O impacto da COVID-19 mediado pela resiliência humana em microempreendores do ramo da beleza

OSHIO, A.; TAKU, K.; HIRANO, M.; SAEED, G. Resilience and Big Five Personality Traits: a meta-analysis. Personality and Individual Differences, v. 127, p. 54-60, 2018. DOI: https://doi.org/10.1016/j.paid.2018.01.048.

PERIM, P. C.; DIAS, C. S.; CORTE-REAL, N. J.; ANDRADE, A. L.; FONSECA, A. M. Análise fatorial confirmatória da versão Brasileira da Escala de Resiliência (ER-Brasil). Gerais: Revista Interinstitucional de Psicologia [online], Juiz de Fora, v. 8, n. 2, p. 373-384, 2015. Disponível em: http://pepsic.bvsalud.org/scielo.php?script=sci_arttext\&pid=S1983$82202015000300007 \&$ lng=pt\&nrm=iso. Acesso em: 19 nov. 2020.

PESSOTTI, C. F. C.; FONSECA, L. C.; TEDRUS, G. M. A. S.; LALON, D. T. Family caregivers of elderly with dementia relationship between religiosity, resilience, quality of life and burden. Dementia \& Neuropsychologia, São Paulo, v. 12, n. 4, p. 408-414, out./dez., 2018. DOI: http://dx.doi.org/10.1590/1980-57642018dn12-040011.

PORTAL DO EMPREENDEDOR. Estatísticas. Total de Microempreendedores Individuais. 2020. Disponível em: http://www.portaldoempreendedor.gov.br/estatisticas. Acesso em: 13 abr. 2020.

RICE, V.; LIU, B. Personal resilience and coping with implications for work. Part I: a review. Work (Reading, Mass), v. 54, n. 2, p. 325-333, 2016. DOI: https://doi.org/10.3233/wor-162300.

ROBERTSON, I. T.; COOPER, C. L.; SARKAR, M.; CURRAN, T. Resilience training in the workplace from 2003 to 2014: a systematic review. Journal of Occupational and Organizational Psychology, v. 88, n. 2, p. 533-562, 2015. DOI: https://doi.org/10.1111/joop.12120.

RODRIGUES, T.; RIBEIRO, A. S.; VASCONCELHOS, L.; ROBERT, B. Teste diagnóstico de resiliência potencial: o radar da resiliência organizacional. Revista de Gestão dos Países de Língua Portuguesa, Lisboa, Portugal, v. 16, n. 1, p. 44-64, 2017. DOI: https://doi.org/10.12660/rgplp.v16n1.2017.78394.

ROOK, C.; SMITH, L.; JOHNSTONE, J.; ROSSATO, C.; SÁNCHEZ, G. F. L.; SUÁREZ, A. D.; ROBERTS, J. Reconceptualizing workplace resilience - A cross-disciplinary perspective. Anales de Psicología/Annals of Psychology, v. 34, n. 2, p. 332-339, 2018. DOI: https://doi.org/10.6018/analesps.34.2.299371.

SERVIÇO BRASILEIRO DE APOIO ÀS MICRO E PEQUENAS EMPRESAS - SEBRAE. Você sabe o que é um Microempreendedor Individual - MEI? Disponível em: https://blog.sebraesc.com.br/voce-sabe-o-que-e-um-microempreendedor-individual-mei/. Acesso em: 13 abr. 2020.

SERVIÇO DE APOIO AS MICRO E PEQUENAS EMPRESAS - SEBRAE. Boletim de impactos da Covid-19 nos pequenos negócios. 2. ed. 3 abr. 2020. Disponível em: https://www.sebrae.com.br/sites/PortalSebrae/impactos-e-tendencias-da-covid-19-nos- 
Aline Francilurdes Nery do Vale, Juliana Carvalho de Sousa, Agostinha Mafalda Barra de Oliveira, Suzana Virgínia da Costa Regis e Joyce Silva Soares de Lima

pequenos negocios,5e8fbd0c7d711710VgnVCM1000004c00210aRCRD. Acesso em 13 abr. 2020.

SHIN, Y.; KIM, S. M.; KIM, H.; MIN, K. J.; YOO, S. K.; KIM, E. J.; JEON, S. W. Resilience as a protective factor for depressive mood and anxiety among Korean employees. Journal of Korean Medical Science, n. 34, v. 27, p. 1-14, 2019. DOI:

http://doi.org/10.3346/jkms.2019.34.e188.

SILVA JÚNIOR, E. G. D.; EULÁLIO, M. C.; SOUTO, R. Q.; SANTOS, K. L.; MELO, R. L. P.; LACERDA, A. R. The capacity for resilience and social support in the urban elderly. Ciência \& Saúde Coletiva, Rio de Janeiro, v. 24, p. 7-16, 2019. DOI: https://doi.org/10.1590/141381232018241.32722016.

SILVA, P. M. M.; EL-AOUAR, W. A.; SILVA, A. W. P.; CASTRO, A. B. C. B. C.; SOUSA, J. C. Resiliência do empreendedorismo feminino. Gestão e Sociedade, Belo Horizonte, v. 13, n. 34, p. 2629-2649, jan./abr., 2019. DOI: http://dx.doi.org/10.21171/ges.v13i34.2346.

SINCORÁ, L. A.; OLIVEIRA, M. P. V.; ZANQUETTO-FILHO, H.; LADEIRA, M. B. Business analytics leveraging resilience in organizational processes. RAUSP Management Journal, São Paulo, $v$. 53, n. 3, p. 385-403, jul./set., 2018. DOI: http://dx.doi.org/10.1108/rausp-04-2018-002.

VASCONCELOS, I. F. F. G. V.; CYRINO, A. B.; D'OLIVEIRA, L. M.; PRALLON, E. P. Resiliência organizacional e inovação sustentável: um estudo sobre o modelo de gestão de pessoas de uma empresa brasileira de energia. Cadernos Ebape Br., São Paulo, v. 13, n. 4, p. 910-929, out./dez., 2015. DOI: http://dx.doi.org/10.1590/1679-395155896.

WAGNILD, G. M. Discovering Your Resilience Core. Resiliencescale.com, 2010. Disponível em: http://resiliencescale.net/papers.html. Acesso em: 8 maio 2020.

WAGNILD, G. M.; YOUNG, H. M. Development and psychometric evaluation of the Resilience Scale. Journal Nursing Measurement, v. 1, n. 2, p. 165-178, 1993. Disponível em:

https://scinapse.io/papers/31456746. Acesso em: 10 maio 2020.

XIAO, H.; ZHANG, Y.; KONG, D.; LI, S.; YANG, N. The effects of social support on sleep quality of medical staff treating patients with Coronavirus Disease 2019 (Covid-19) in January and February 2020 in China, Medical Science Monitor, v. 26, n. 5, 2020. DOI: https://doi.org/10.12659/MSM.923549. 